\title{
Plasma Fibrinogen Level and the Risk of Major Cardiovascular Diseases and Nonvascular Mortality An Individual Participant Meta-analysis
}

Fibrinogen Studies Collaboration*

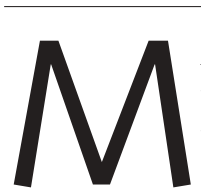
ANY PROSPECTIVE EPIDEmiological studies have reported positive associations between the risk of coronary heart disease (CHD) and plasma fibrinogen levels. ${ }^{1-37}$ Fibrinogen is the major coagulation protein in blood by mass, the precursor of fibrin, and an important determinant of blood viscosity and platelet aggregation..$^{38-41}$ Because fibrinogen levels can be reduced considerably by lifestyle interventions that also affect levels of established risk factors (such as regular exercise, smoking cessation, and moderate alcohol consumption), there is interest in the possibility that measurement (or modification) of fibrinogen may help in disease prediction or prevention. ${ }^{38-40,42}$ A meta-analysis of published data from 18 such studies, involving about 4000 CHD cases, indicated a relative risk of 1.8 (95\% confidence interval $[\mathrm{CI}], 1.6-2.0$ ) per 1-g/L increase in plasma fibrinogen level. ${ }^{43}$ However, such analyses are not able to provide detailed assessments of the nature of any independent association of fibrinogen level with CHD or with other vascular and nonvascular outcomes. $^{43-45}$

This meta-analysis differs from previous analyses in several ways that should increase its reliability and scientific value. First, it is large and comprehensive: the data comprise 6944 first nonfatal myocardial infarction (MI) or stroke events and 13210 deaths (cause-

Context Plasma fibrinogen levels may be associated with the risk of coronary heart disease (CHD) and stroke.

Objective To assess the relationships of fibrinogen levels with risk of major vascular and with risk of nonvascular outcomes based on individual participant data.

Data Sources Relevant studies were identified by computer-assisted searches, hand searches of reference lists, and personal communication with relevant investigators.

Study Selection All identified prospective studies were included with information available on baseline fibrinogen levels and details of subsequent major vascular morbidity and/or cause-specific mortality during at least 1 year of follow-up. Studies were excluded if they recruited participants on the basis of having had a previous history of cardiovascular disease; participants with known preexisting CHD or stroke were excluded.

Data Extraction Individual records were provided on each of 154211 participants in 31 prospective studies. During 1.38 million person-years of follow-up, there were 6944 first nonfatal myocardial infarctions or stroke events and 13210 deaths. Causespecific mortality was generally available. Analyses involved proportional hazards modeling with adjustment for confounding by known cardiovascular risk factors and for regression dilution bias.

Data Synthesis Within each age group considered (40-59, 60-69, and $\geq 70$ years), there was an approximately log-linear association with usual fibrinogen level for the risk of any $\mathrm{CHD}$, any stroke, other vascular (eg, non-CHD, nonstroke) mortality, and nonvascular mortality. There was no evidence of a threshold within the range of usual fibrinogen level studied at any age. The age- and sex- adjusted hazard ratio per 1-g/L increase in usual fibrinogen level for CHD was $2.42(95 \%$ confidence interval [CI], 2.24-2.60); stroke, 2.06 (95\% Cl, 1.83-2.33); other vascular mortality, $2.76(95 \% \mathrm{Cl}$, 2.28-3.35); and nonvascular mortality, 2.03 ( $95 \% \mathrm{Cl}, 1.90-2.18)$. The hazard ratios for $\mathrm{CHD}$ and stroke were reduced to about 1.8 after further adjustment for measured values of several established vascular risk factors. In a subset of 7011 participants with available C-reactive protein values, the findings for CHD were essentially unchanged following additional adjustment for $\mathrm{C}$-reactive protein. The associations of fibrinogen level with CHD or stroke did not differ substantially according to sex, smoking, blood pressure, blood lipid levels, or several features of study design.

Conclusions In this large individual participant meta-analysis, moderately strong associations were found between usual plasma fibrinogen level and the risks of CHD, stroke, other vascular mortality, and nonvascular mortality in a wide range of circumstances in healthy middle-aged adults. Assessment of any causal relevance of elevated fibrinogen levels to disease requires additional research.

JAMA. 2005;294:1799-1809

www.jama.com

*The Authors/Writing Committee, Authors/Members, and Other Members of the Fibrinogen Studies Collaboration are listed at the end of this article. Corresponding Author: John Danesh, DPhil, Depart- ment of Public Health and Primary Care, Institute of Public Health, University of Cambridge, Strangeways Site, Wort's Causeway, Cambridge CB1 8RN, UK (john .danesh@phpc.cam.ac.uk). 
specific mortality information is generally available among 154211 participants in 31 studies). Second, individual records are available for all participants, allowing detailed analyses at different plasma fibrinogen levels and in different circumstances (such as by age, in men and women, in smokers and nonsmokers, and at different plasma lipid levels and blood pressure levels). Third, harmonization of individual records by baseline variables allows a consistent approach to adjust for potential confounding factors. Fourth, individuals with known preexisting CHD and stroke are excluded, limiting any effects of clinically evident disease on plasma fibrinogen level (ie, minimizing any "reverse association") ${ }^{46}$ Fifth, there is correction for within-person variations in plasma fibrinogen levels (ie, "regression dilution" 47 ) because 27247 participants had serial measurements taken during follow-up. The main aim of this metaanalysis is to combine primary data from all relevant prospective studies to produce reliable estimates of the associations of plasma fibrinogen with CHD (and, secondarily, with stroke, other vascular mortality, and nonvascular mortality), incorporating adjustment for confounding caused by established cardiovascular risk factors and correction for regression dilution. ${ }^{48}$

\section{METHODS \\ Study Selection, Data Collection, and End Points}

As described previously, ${ }^{48}$ collaboration was sought from investigators of all published prospective studies among population-based samples (ie, participants were not selected on the basis of a previous history of cardiovascular disease) in which data on plasma fibrinogen level, date of birth (or age), and sex had been recorded at a baseline screening visit, and major vascular morbidity and/or cause-specific mortality and age at event or death had been routinely sought during at least 1 year of follow-up. Individual participant data were contributed from all relevant stud- ies that were identified by previously published meta-analyses, through updated computer searches of databases including MEDLINE and Embase, and by extensive discussions with the investigators (referred to herein as collaborators).

This study was exempt from institutional review board approval by the Cambridgeshire ethics review committee because all 31 studies included were published previously and had each previously received local institutional review board approvals and consent from participants.

If available, data also were collected on history of heart disease, stroke, or diabetes; cigarette smoking habits (including, when available, current and previous smoking habits, amount smoked, and duration); alcohol consumption; systolic and diastolic blood pressure; serum lipid levels (including triglycerides, total, low-density lipoprotein and high-density lipoprotein cholesterol); leukocyte count; serum levels of albumin and

\begin{tabular}{|c|c|c|c|c|c|c|}
\hline & \multirow[b]{2}{*}{$\begin{array}{l}\text { Top } \\
\text { Third }\end{array}$} & \multirow[b]{2}{*}{$\begin{array}{l}\text { Middle } \\
\text { Third }\end{array}$} & \multirow[b]{2}{*}{$\begin{array}{l}\text { Bottom } \\
\text { Third }\end{array}$} & \multicolumn{2}{|l|}{ z Values } & \multirow[b]{2}{*}{$\begin{array}{l}\text { No. of } \\
\text { Available Individuals }\end{array}$} \\
\hline & & & & $\begin{array}{l}\text { Adjusted for Age, Sex, } \\
\text { and Cohort }\end{array}$ & $\begin{array}{l}\text { Adjusted } \\
\text { Further* }\end{array}$ & \\
\hline \multicolumn{7}{|c|}{ No. (\%) } \\
\hline Men & 35197 (69) & 37357 (73) & $40229(77)$ & -27.6 & -36.1 & 154211 \\
\hline Current smoker & $21300(42)$ & $16911(33)$ & $13191(25)$ & 72.0 & 77.9 & 154211 \\
\hline Consume alcohol & $25922(67)$ & $28521(72)$ & $31363(78)$ & -25.9 & -27.5 & 118794 \\
\hline History of diabetes & $2774(7)$ & $2264(6)$ & $1939(5)$ & 12.6 & 6.9 & 119708 \\
\hline \multicolumn{7}{|c|}{ Mean (SD) } \\
\hline Fibrinogen, g/L & $3.74(0.7)$ & $2.95(0.5)$ & $2.36(0.4)$ & & & 154211 \\
\hline Age, y & $55.4(9.1)$ & $53.8(9.4)$ & $51.8(9.5)$ & 81.4 & 75.3 & 154211 \\
\hline \multicolumn{7}{|l|}{ Blood pressure, $\mathrm{mm} \mathrm{Hg}$} \\
\hline Diastolic & $82.7(12.7)$ & $82.1(12.4)$ & $81.2(11.9)$ & 18.3 & 8.0† & 154170 \\
\hline Body mass index $\neq$ & $26.7(4.6)$ & $26.1(4.0)$ & $25.4(3.8)$ & 52.8 & 54.1 & 154211 \\
\hline \multicolumn{7}{|l|}{ Cholesterol, mmol/L } \\
\hline Low-density lipoprotein & $3.89(1.09)$ & $3.76(1.04)$ & $3.57(1.03)$ & 38.1 & 33.1 & 101176 \\
\hline High-density lipoprotein & $1.31(0.39)$ & $1.35(0.40)$ & $1.39(0.42)$ & -47.5 & -34.9 & 114006 \\
\hline Triglycerides, mmol/L & $1.67(1.19)$ & $1.60(1.12)$ & $1.55(1.23)$ & 14.1 & -5.7 & 94901 \\
\hline Leukocyte count, $\times 10^{9} / \mathrm{L}$ & $6.7(2.1)$ & $6.1(1.9)$ & $5.8(1.8)$ & 52.3 & 38.6 & 52072 \\
\hline Albumin, $\mathrm{g} / \mathrm{L}$ & $42.5(4.6)$ & $43.1(4.5)$ & $43.3(4.4)$ & -18.3 & -18.9 & 49804 \\
\hline C-reactive protein, mg/L & $4.8(6.8)$ & $2.2(3.6)$ & $1.4(1.8)$ & 29.8 & 27.8 & 7011 \\
\hline \multicolumn{7}{|c|}{$\begin{array}{l}\text { SI conversion factors: To convert albumin to } \mathrm{g} / \mathrm{dL} \text {, divide by } 10 \text {; fibrinogen to } \mathrm{mg} / \mathrm{dL} \text {, divide by } 0.01 \text {; high-density lipoprotein, low-density lipoprotein, and total cholesterol to } \mathrm{mg} / \mathrm{dL} \text {, } \\
\text { divide by } 0.0259 ; \text { triglycerides to } \mathrm{mg} / \mathrm{dL} \text {, divide by } 0.0113 \text {. } \\
\text { *Values adjusted for age, sex, and cohort, and also adjusted for systolic blood pressure, total cholesterol, body mass index, and current smoking. } \\
\text { †Not adjusted for systolic blood pressure. } \\
\ddagger \text { Calculated as weight in kilograms divided by height in meters squared. }\end{array}$} \\
\hline
\end{tabular}


C-reactive protein; and use of hormone treatments.

Information on cause-specific mortality was provided by collaborators in the greatest detail available. International Classification of Diseases coding to at least 3 digits was used and was based on death certificates (and all but one $^{23}$ of the contributing studies reported that medical records, autopsy findings, or other supplementary sources further helped to classify deaths).$^{48}$ Codes from versions 8,9 , and 10 of the International Classification of Diseases were accepted along with cohort-specific codes (details are available at: http://www.phpc.cam.ac.uk /FSC/docs/JAMA_2005_Webtab1 .pdf). All studies reported use of standard definitions of MI (eg, clinical features, characteristic electrocardiogram changes, and marked elevations in blood levels of cardiac enzymes) and were typically based on criteria from the Monitoring Trends and Determinants in Cardiovascular Disease (MONICA) study or from the World Health Organization. In studies that distinguished cases of "possible," "probable," "suspect," or "silent" MI from "confirmed" MI, any cases in the nonconfirmed categories were excluded from analyses. The large majority of studies reported diagnosing strokes on the basis of typical clinical features and characteristic changes on computed tomographic and/or magnetic resonance imaging brain scans, but only about half provided attribution of stroke subtype (such as cerebral ischemia, cerebral hemorrhage, or subarachnoid hemorrhage) ${ }^{48}$ Prior to the conversion of the data from each study to a standard format for incorporation into a central database, the data were checked for consistency by the members of the secretariat (see list at end of this article) and any queries were referred back to the collaborators prior to the final harmonization of the data.

\section{Statistical Analyses}

Because there are substantial differences in the mean (SD) values of fibrinogen across the contributing studies (partly due to differences in assay methods [involving clotting rate, clot weight, and various immunologic assays] and in fibrinogen standards [details are available at: http://www.phpc.cam.ac.uk /FSC/docs/JAMA_2005_Webfig 1 .pdf]), the present analyses involved comparisons of cases with noncases within each cohort. The prespecified unit of comparison in this metaanalysis was a $1-\mathrm{g} / \mathrm{L}$ increase in fibrinogen, with parallel analyses conducted for standardized increases in plasma fibrinogen (ie, per SD of fibrinogen values for each study) to allow for variations in fibrinogen levels across studies. Because the 2 approaches yielded similar patterns of findings, only the former are shown herein (the parallel analyses are available on request from the secretariat).
All analyses used the Cox proportional hazards model, stratified for study, sex, and, in the 2 studies ${ }^{15,37}$ that randomized participants to different interventions, for trial group. The assumptions of the proportionality of hazards for fibrinogen level were satisfied in each of the 31 studies, which were assessed by plots of Schoenfeld residuals (data available on request). Each participant contributed only either the first nonfatal end point or death recorded at age 40 years or older (ie, deaths preceded by nonfatal CHD or stroke were not included in the analyses). These analyses were used in 2 ways to describe the dose-response relationships. ${ }^{49}$ First, to investigate the shape of the association, the hazard ratios (HRs) for groups defined by fifths of baseline values of fibrinogen within

Figure 1. Age-Specific, Sex- and Cohort-Adjusted Hazard Ratios for Cardiovascular Disease and Nonvascular Mortality by Fifths of Usual Fibrinogen Level

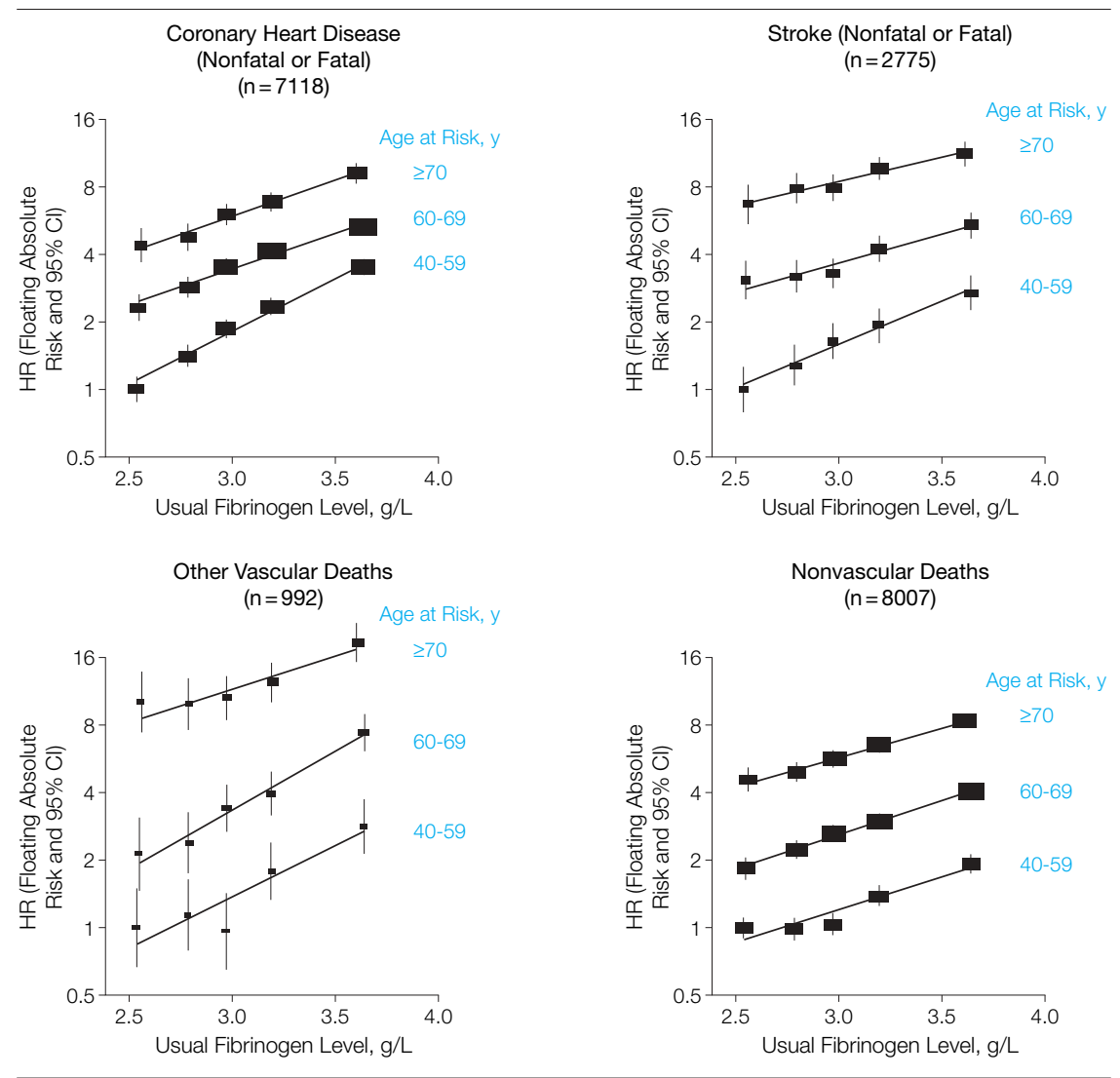

Fifths of usual fibrinogen level were calculated within each study. Curves are fitted by log-linear regression lines. $\mathrm{Cl}$ indicates confidence interval; $\mathrm{HR}$, hazard ratio. The size of the data markers is proportional to the inverse of the variances of the HR estimates. 
each study were calculated and the 95\% CIs were estimated from the floated variances that reflect the amount of information underlying each group (including the reference group). ${ }^{50}$ A proportional or log scale was used for plotting disease rates. Second, if these analyses were consistent with a loglinear association, regression coefficients were calculated for the percentage change in risk associated with a 1 -g/L difference in fibrinogen level. Heterogeneity of these associations was investigated with respect to mean age at baseline, other prespecified personal characteristics (eg, sex, smoking status, body mass index, blood lipid levels, and blood pressure level), and study characteristics (eg, geographical setting, sampling framework, and fibrinogen assay method). A random effect analysis also was used to take further account of between-study variation.

Analyses were adjusted for the effects of age at screening, smoking sta- tus, measured values of systolic blood pressure, total cholesterol level, and body mass index. More comprehensive adjustment for possible confounders was made in the subset of studies that had recorded details on alcohol consumption, subtypes of serum lipid levels, C-reactive protein, and history of diabetes. Statistical analyses were performed using STATA software version 8 (STATA Corp, College Station, Tex) and SAS software version 8 (SAS Institute Inc, Cary, NC). Analyses for the 2 nested case-control studies ${ }^{3,22}$ (comprising a total of 439 CHD cases and 1554 controls) yielded essentially similar findings to those for the 31 cohort studies, albeit with much wider $95 \%$ CIs (data not shown). For results from individual studies, 99\% CIs were used to make some allowance for the increased scope for random error in multiple comparisons and 95\% CIs were used for combined analyses. Unless stated otherwise, all analyses have ex- cluded the 1616 individuals with fibrinogen levels greater than $5.62 \mathrm{~g} / \mathrm{L}$ (ie, the highest $1 \%$ ) due to the potential distortions arising from assay imprecision at such levels ${ }^{51}$ and from acutephase reactions. ${ }^{52}$

\section{Correction for Regression Dilution}

Fifteen of the contributing studies ${ }^{23-37}$ provided data on 27247 individuals and provided 2 or more fibrinogen level measurements. Most of the serial fibrinogen level measurements were taken within the first decade of follow-up. Baseline fibrinogen levels were used to divide individuals into fifths, and the ratio of the range between the mean values of the repeat measurements in the top compared with the bottom fifth was used to estimate regression dilution ratios for various intervals ${ }^{42,47,49}$ (and similar results were obtained using the Rosner regression method ${ }^{53}$; details are available at: http://www.phpc.cam.ac.uk/FSC /docs/JAMA_2005_Webfig2.pdf). The

Figure 2. Age-Specific Hazard Ratios for Cardiovascular Disease and Nonvascular Mortality per 1-g/L Increase in Usual Fibrinogen Level

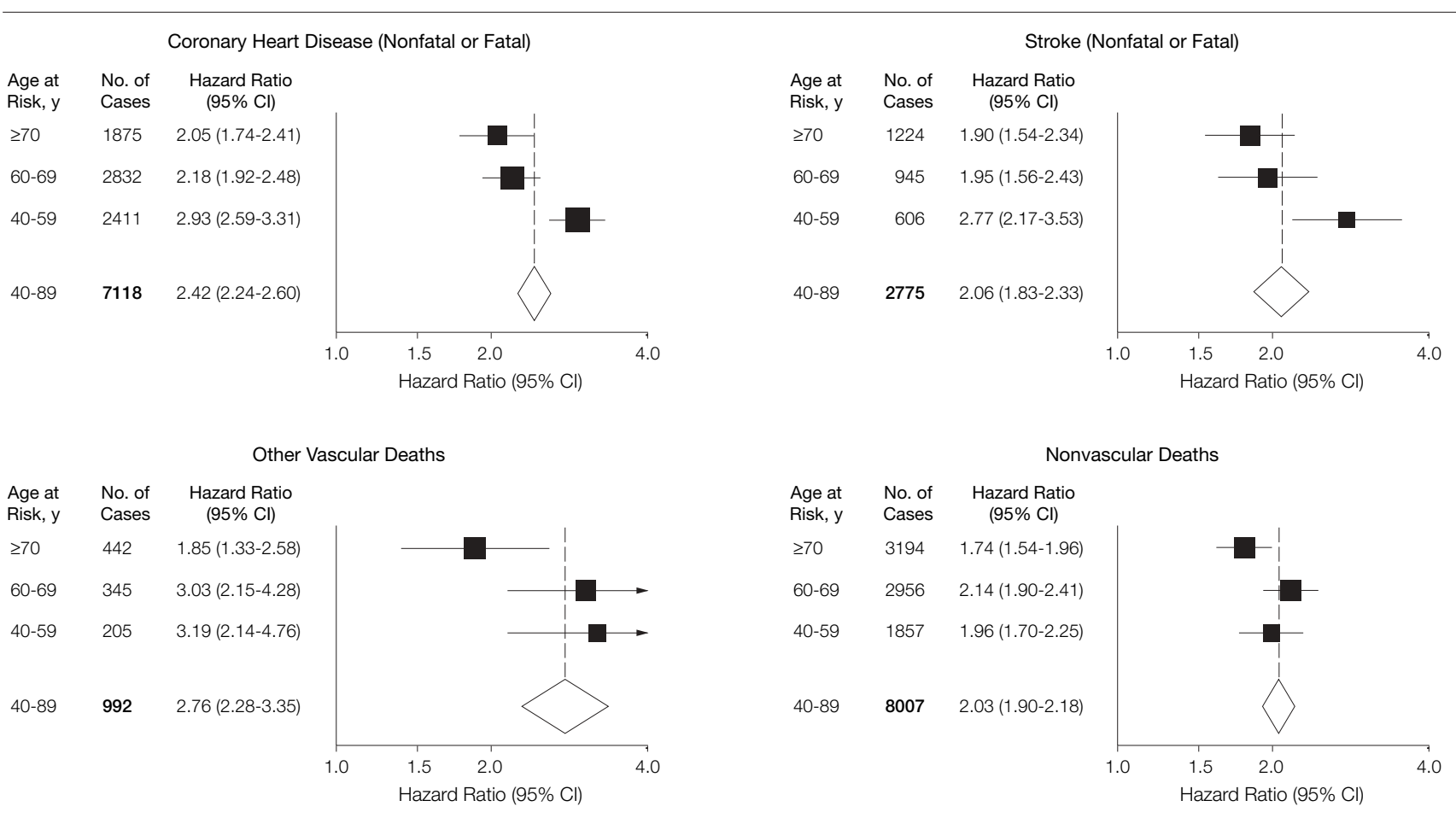

Fibrinogen level adjusted for age at screening and stratified on sex, cohort, and trial group. $\mathrm{Cl}$ indicates confidence interval. The size of the data markers is proportional to the inverse of the variances of the hazard ratios. 
regression dilution ratio declined moderately with increasing intervals between measurements, with a value of about 0.5 for the first 5 years from the initial fibrinogen level measurement, but data were insufficient to estimate this value reliably for more prolonged durations of follow-up. Hence, the regression coefficient and SE relating risk to usual (ie, long-term average) fibrinogen level was estimated as approximately twice (ie, 1/0.5) the regression coefficient and its SE.

\section{RESULTS}

This meta-analysis includes 154211 participants in 31 prospective studies with available individual records, no known history of previous CHD (ie, MI or angina, which was defined in each study ${ }^{48}$ ) or stroke at baseline, fibrinogen levels of $5.62 \mathrm{~g} / \mathrm{L}$ or lower, and any nonfatal CHD and stroke events or any deaths recorded for individuals aged 40 years or older. Of these participants, 115658 (75\%) were from Europe, 27758 (18\%) were from North America, and 10795 (7\%) were from Japan. During 1.38 million person-years of follow-up (mean [SD], 8.9 [4.9] years to first event or death), there were 4681 nonfatal MIs, 2263 nonfatal strokes, and 13210 deaths comprising 2437 deaths attributed to CHD, 512 to stroke, 992 to other vascular causes (including 175 due to aortic aneurysm, 125 to heart failure, and 88 to acute pulmonary heart disease), 8007 to nonvascular causes (of which 4856 were due to cancer), and 1262 to unknown causes (details by cohort available at: http://www.phpc.cam.ac .uk/FSC/docs/JAMA_2005_Webtab2 .pdf).

There were generally strong and highly significant positive associations between plasma fibrinogen levels and values of several established risk factors at baseline, such as age, cigarette smoking, serum levels of total and low-density lipoprotein cholesterol and triglycerides, blood pressure, body mass index, and history of diabetes (and, in the subset with data available on inflammatory factors, with leukocyte count and C-reactive protein values)
(TABLE 1). There also were highly significant inverse associations between plasma fibrinogen level and male sex, alcohol consumption, and serum levels of high-density lipoprotein cholesterol and albumin.

\section{Age-Specific HRs for Major End Points}

There was a log-linear association with usual fibrinogen (plotted by fifths of values) for the risk of nonfatal or fatal CHD, nonfatal or fatal stroke, other vascular mortality (eg, non-CHD, nonstroke), and nonvascular mortality. There was no threshold in the range of available fibrinogen levels at which lower levels were no longer associated with lower risk (FIGURE 1). For usual fibrinogen levels, all 5 data points within each age group representing patients who had CHD, stroke, or nonvascular mortality are reasonably well fitted by the log-linear agespecific regression lines in Figure 1, although the trend is less distinct among the small numbers of participants who

Figure 3. Hazard Ratios for Cardiovascular Disease and Nonvascular Mortality per 1-g/L Increase in Usual Fibrinogen Level

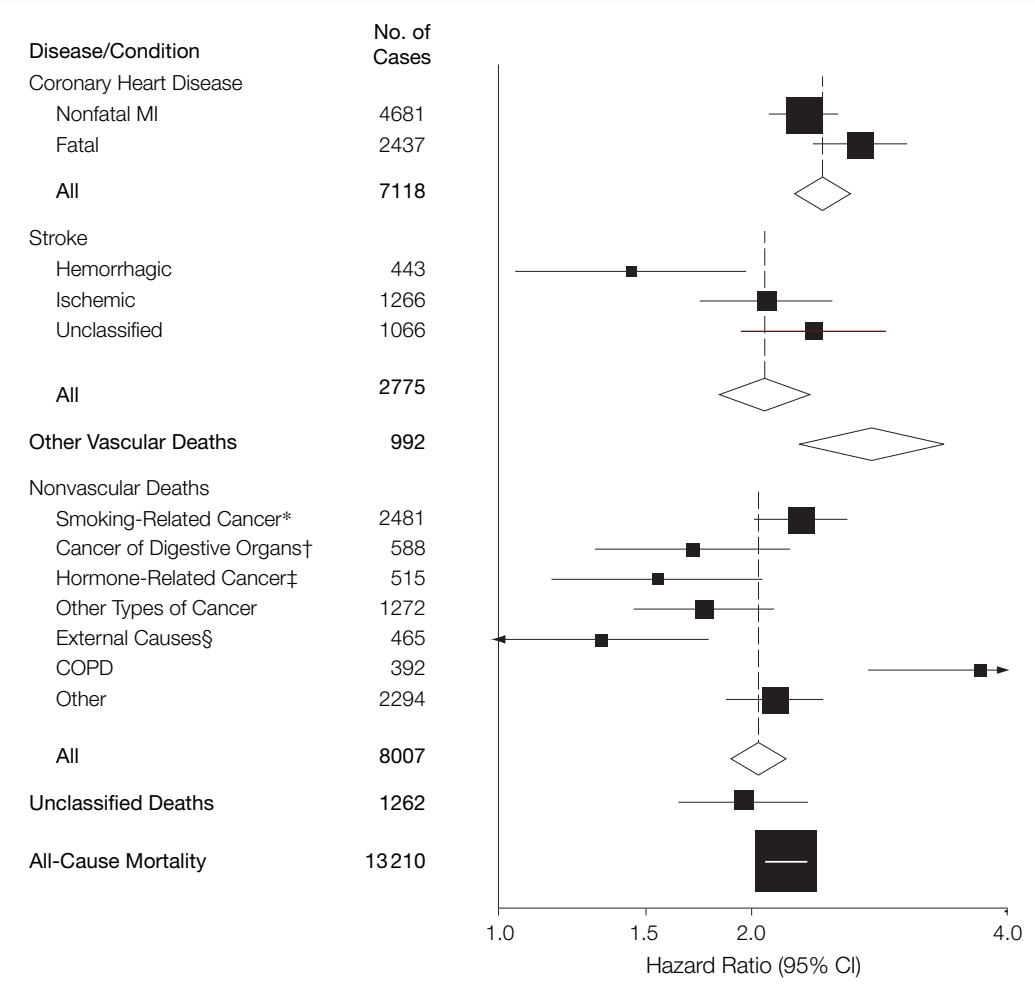

Fibrinogen level adjusted for age at screening and stratified by sex, cohort, and trial group. $\mathrm{Cl}$ indicates confidence interval; COPD, chronic obstructive pulmonary disease. The size of the data markers is proportional to the inverse of the variances of the hazard ratios.

* Includes International Classification of Diseases, 10th Revision (ICD-10) codes C00-C02 for cancer of the lip and tongue; ICD-10 codes C03-C06 for cancer of the gum, mouth, and palate; ICD-10 codes C09-C14 for cancer of the tonsil, oropharynx, nasopharynx, pyriform sinus, and hypopharynx; ICD-10 code C22 for cancer of the liver and intrahepatic bile; ICD-10 code C25 for cancer of the pancreas; ICD-10 codes C30-C34 for cancer of the nasal cavity and middle ear, larynx, trachea, and bronchus and lung; ICD-10 code C53 for cancer of the cervix uteri; ICD-10 codes C64-C68 for cancer of the kidney, renal pelvis, ureter, and bladder; and ICD-10 code C92 for cancer of the myeloid leukemia.

tIncludes ICD-10 codes C17-C21 for cancer of the small intestine, rectosigmoid junction, rectum, and anus; $I C D-10$ codes $C 23-C 24$ for cancer of the gallbladder and biliary tract.

\#Includes ICD-10 code C50 for cancer of the breast; ICD-10 codes C54-C56 for cancer of the corpus uteri, uterus, and ovary; ICD-10 codes C61-C62 for cancer of the prostate and testis; and ICD-10 code C73 for cancer of the thyroid gland.

§Includes ICD-10 codes S00-T98 for injury, poisoning, and certain other consequences of external cause and ICD-10 codes V01-98 for morbidity and mortality. 
had other vascular deaths. The slopes of these regression lines were used to calculate the age-specific HRs for each of the major end points associated with a 1 -g/L increase in usual fibrinogen level (FIGURE 2). The strengths of the association with usual plasma fibrinogen level declined to some extent with increasing age at event for CHD and for stroke. At ages 60 to 69 years, such differences in usual fibrinogen level were associated with about a 2-fold increase in risk for each of these outcomes. The HRs were about $50 \%$ more extreme for CHD and for stroke at ages 40 to 59 years compared with older ages, but the association with each of the major end points remained moderately strong even at older ages.

\section{Overall HRs With Major End Points}

Associations of fibrinogen level with different vascular and nonvascular outcomes are shown in FIGURE 3 and TABLE 2. For any CHD, the HR per

Table 2. Hazard Ratios for Cardiovascular Disease and Nonvascular Mortality per 1-g/L Increase in Usual Fibrinogen Level*

\begin{tabular}{|c|c|c|c|}
\hline \multirow[b]{2}{*}{ Disease/Condition } & \multicolumn{3}{|c|}{ Hazard Ratio (95\% Confidence Interval) } \\
\hline & $\begin{array}{l}\text { All Participants } \\
(\mathrm{N}=154211)\end{array}$ & $\begin{array}{c}\text { Never-Smokers } \\
\text { Only† } \\
(\mathrm{n}=45369)\end{array}$ & $\begin{array}{c}\text { Events/Deaths } \\
\text { After First } 5 \text { y } \\
\text { of Follow-Up } \\
(n=123 \text { 439) }\end{array}$ \\
\hline $\begin{array}{r}\mathrm{CHD} \\
\text { All }\end{array}$ & $2.42(2.24-2.60)$ & $2.54(2.10-3.09)$ & $2.48(2.24-2.74)$ \\
\hline Nonfatal Ml & $2.30(2.10-2.52)$ & $2.29(1.81-2.91)$ & $2.36(2.06-2.69)$ \\
\hline Fatal & $2.68(2.36-3.03)$ & $3.13(2.25-4.36)$ & $2.68(2.29-3.14)$ \\
\hline $\begin{array}{l}\text { Stroke } \\
\text { All }\end{array}$ & $2.06(1.83-2.33)$ & $1.87(1.43-2.45)$ & $1.87(1.57-2.24)$ \\
\hline Hemorrhagic & $1.44(1.05-1.96)$ & $1.37(0.70-2.70)$ & $1.45(0.91-2.29)$ \\
\hline Ischemic & $2.08(1.74-2.48)$ & $1.76(1.22-2.53)$ & $1.93(1.47-2.52)$ \\
\hline Unclassified & $2.36(1.94-2.86)$ & $2.48(1.51-4.07)$ & $1.99(1.51-2.62)$ \\
\hline $\begin{array}{l}\text { All CHD, all stroke, and } \\
\text { other vascular deaths }\end{array}$ & $2.35(2.21-2.49)$ & $2.31(1.91-2.79)$ & $2.29(2.11-2.49)$ \\
\hline $\begin{array}{c}\text { Non-CHD, nonstroke } \\
\text { vascular deaths }\end{array}$ & $2.76(2.28-3.35)$ & $2.41(1.54-3.77)$ & $2.20(1.70-2.84)$ \\
\hline $\begin{array}{l}\text { Nonvascular deaths } \\
\text { All }\end{array}$ & $2.03(1.90-2.18)$ & $1.99(1.67-2.36)$ & $1.88(1.71-2.06)$ \\
\hline COPD & $3.70(2.75-4.97)$ & $5.49(1.73-17.45)$ & $4.52(3.11-6.57)$ \\
\hline Other & $2.12(1.87-2.42)$ & $2.03(1.55-2.66)$ & $2.19(1.85-2.60)$ \\
\hline $\begin{array}{l}\text { Types of cancer } \\
\text { Smoking-related§ }\end{array}$ & $2.28(2.01-2.58)$ & $1.56(0.99-2.47)$ & $2.00(1.70-2.35)$ \\
\hline Digestive organs $\|$ & $1.70(1.31-2.21)$ & $3.00(1.67-5.41)$ & $1.46(1.03-2.05)$ \\
\hline Colorectal & $1.71(1.30-2.25)$ & $2.84(1.51-5.35)$ & $1.56(1.09-2.24)$ \\
\hline Hormone-related & $1.54(1.16-2.05)$ & $1.66(0.97-2.86)$ & $1.16(0.81-1.68)$ \\
\hline Other & $1.75(1.45-2.12)$ & $2.66(1.68-4.20)$ & $1.44(1.14-1.83)$ \\
\hline All-cause mortality & $2.18(2.07-2.31)$ & $2.13(1.86-2.43)$ & $2.03(1.89-2.17)$ \\
\hline External causes\# & $1.32(0.99-1.77)$ & $1.22(0.67-2.24)$ & $1.32(0.87-2.00)$ \\
\hline Unclassified & $1.95(1.64-2.31)$ & $1.38(0.85-2.22)$ & $1.93(1.59-2.33)$ \\
\hline
\end{tabular}

Abbreviations: CHD, coronary heart disease; COPD, chronic obstructive pulmonary disease; MI, myocardial infarction. *Adjusted for age at screening and stratified by sex, cohort, and trial group.

†In restricted analyses, there were $1059 \mathrm{CHD}$ cases (711 nonfatal Ml and 348 fatal), 602 stroke cases (101 hemorrhagic, 337 ischemic, and 164 unclassified), 199 cases of other vascular mortality, 1361 nonvascular deaths, 190 unclassified deaths, and 2217 total deaths.

fln restricted analyses, there were $3712 \mathrm{CHD}$ cases ( 2176 nonfatal Ml and 1536 fatal), 1375 stroke cases (215 hemorrhagic, 596 ischemic, and 564 unclassified), 608 cases of other vascular mortality, 4883 nonvascular deaths, 1015 unclassified deaths, and 8360 total deaths.

SInclude International Classification of Diseases, 10 th Revision (ICD-10) codes for lip and tongue (CO0-CO2); gum, mouth, and palate (C03-C06); tonsil, oropharynx, nasopharynx, pyriform sinus, and hypopharynx (C09-C14); liver and intrahepatic bile (C22); pancreas (C25); nasal cavity, middle ear, larynx, trachea, bronchus, and lung (C30-C34); cervix uteri (C53); kidney, renal pelvis, ureter, and bladder (C64-C68); and myeloid leukemia (C92).

IInclude $/ C D-10$ codes for the small intestine, rectosigmoid junction, rectum, and anus (C17-C21); and gallbladder and biliary tract (C23-C24).

IInclude ICD-10 codes for breast (C50), corpus uteri, uterus, and ovary (C54-C56); prostate and testis (C61-C62); and thyroid gland (C73).

thyroid gland (C73).

\#Include ICD-10 codes for injury, poisoning, and certain other consequences of external cause (S00-T98); and external causes of morbidity and mortality (V01-V98). $1-\mathrm{g} / \mathrm{L}$ increase in usual fibrinogen level was 2.42 (95\% CI, 2.24-2.60); there was a possibly higher HR of 2.68 (95\% CI, 2.36-3.03) for fatal CHD compared with a HR of 2.30 (95\% CI, 2.10-2.52) for nonfatal MI ( $\chi_{1}^{2}$ for heterogeneity $=3.8 ; P=.05)$. For all types of stroke, the corresponding HR was 2.06 (95\% CI, 1.83-2.33). For ischemic stroke, the HR was 2.08 (95\% CI, 1.74-2.48); hemorrhagic stroke, 1.44 (95\% CI, 1.05-1.96); and stroke attributed to unclassified causes, 2.36 (95\% CI, 1.942.86) ( $\chi_{2}^{2}$ for heterogeneity $=7.0 ; P=.03$ ) The HR for other vascular mortality (eg, non-CHD, nonstroke) was 2.76 (95\% CI, 2.28-3.35); nonvascular mortality, 2.03 (95\% CI, 1.90-2.18); and unclassified deaths, 1.95 (95\% CI, 1.642.31). The combined HR for all vascular deaths and events (eg, a combination of all CHD, all stroke, and other vascular deaths) was 2.35 (95\% CI, 2.212.49), which was similar to that for all nonvascular mortality. There were too few cases of particular types of cancer to enable reliable analyses by type of cancer. Apart from a possibly stronger association with smoking-related cancer, subdivision of the aggregate of nonvascular deaths (most of which were cancer) generally did not suggest much more specific associations, although the association with deaths due to external causes was of marginal statistical significance. The HRs for cardiovascular end points were generally similar in analyses restricted to never smokers or to participants with first events (or deaths) recorded after the first 5 years of follow-up compared with the corresponding HRs involving all participants (Table 2).

\section{Assessments of Potential Sources of Heterogeneity and Confounding}

FIGURE 4 and FIGURE 5 show the impact of a 1-g/L increase in usual fibrinogen level on CHD and stroke, respectively, by various study and individuallevel characteristics after adjustment for age, sex, cohort, smoking, blood pressure, total cholesterol, and body mass index. For CHD (Figure 4), there was substantial heterogeneity among the 31 
separate cohorts $\left(\chi_{30}^{2}=84.5 ; P<.001\right.$; details by cohort available at http://www .phpc.cam.ac.uk/FSC/docs/JAMA _2005_Webfig3.pdf). Only some of the heterogeneity is explained by recorded characteristics. There was little evidence that the magnitude of the association between fibrinogen levels and CHD was importantly influenced by sex, blood pressure, or serum cholesterol level, a history of smoking or diabetes, or assay method. There was some evidence of heterogeneity among the findings of the 30 separate studies contributing stroke end points $\left(\chi_{29}^{2}=48.7\right.$; $P=.01$; details by cohort available at: http://www.phpc.cam.ac.uk/FSC/docs /JAMA_2005_Webfig4.pdf), but there were no substantial variations in the associations by characteristics recorded (Figure 5). When the few studies that contributed most to the heterogeneity for each end point were excluded (ie, so that among the remaining studies $P>.05$ for heterogeneity for each end point), the combined HRs were little changed, suggesting the absence of important biases from the studies with more extreme results. Furthermore, use of a method that incorporates heterogeneity into the uncertainty around HRs calculated for each end point yielded only slightly wider $95 \%$ CIs than the fixed-effects model. ${ }^{54}$

TABLE 3 shows the impact of progressive adjustment for baseline values of potential confounding factors on HRs. For CHD and stroke, the age-, sex-, and cohort-adjusted HRs decreased to 1.93 (95\% CI, 1.79-2.08) and 1.75 (95\% CI, 1.55-1.98), respectively, after adjustment for smoking, total cholesterol, blood pressure, and body mass index, and were 1.82 (95\% CI, 1.60-2.06) and 1.82 (95\% CI, 1.54-2.16), respectively, after further adjustment for alcohol consumption, concentrations of lipid subfractions, and history of diabetes in the studies with information on these variables. The substantial decreases in the $\chi^{2}$ statistic for the association with fibrinogen level after these adjustments (from 246 to 87 for CHD and from 97 to 48 for stroke) suggests that a considerable part of the association was due to confounding. Moreover, because these confounding factors may have been measured with some error, substantial residual confounding may remain. ${ }^{55}$ For nonvascular mortality (and, to some extent, for other vascular mortality), the effect of adjustment for potential confounding factors on HRs and on corresponding $\chi^{2}$ statistic values was less marked (Table 3).
The Pearson partial correlation coefficient (adjusted for age) between fibrinogen and log C-reactive protein was 0.47 (95\% CI, 0.45-0.49) in the 7011 participants with available C-reactive protein measurements. Among these 7011 participants, 263 CHD cases were recorded and the HR for CHD per 1-g/L increase in usual fibrinogen level was reduced from

Figure 4. Adjusted Hazard Ratios for Coronary Heart Disease per 1-g/L Increase in Usual Fibrinogen Level

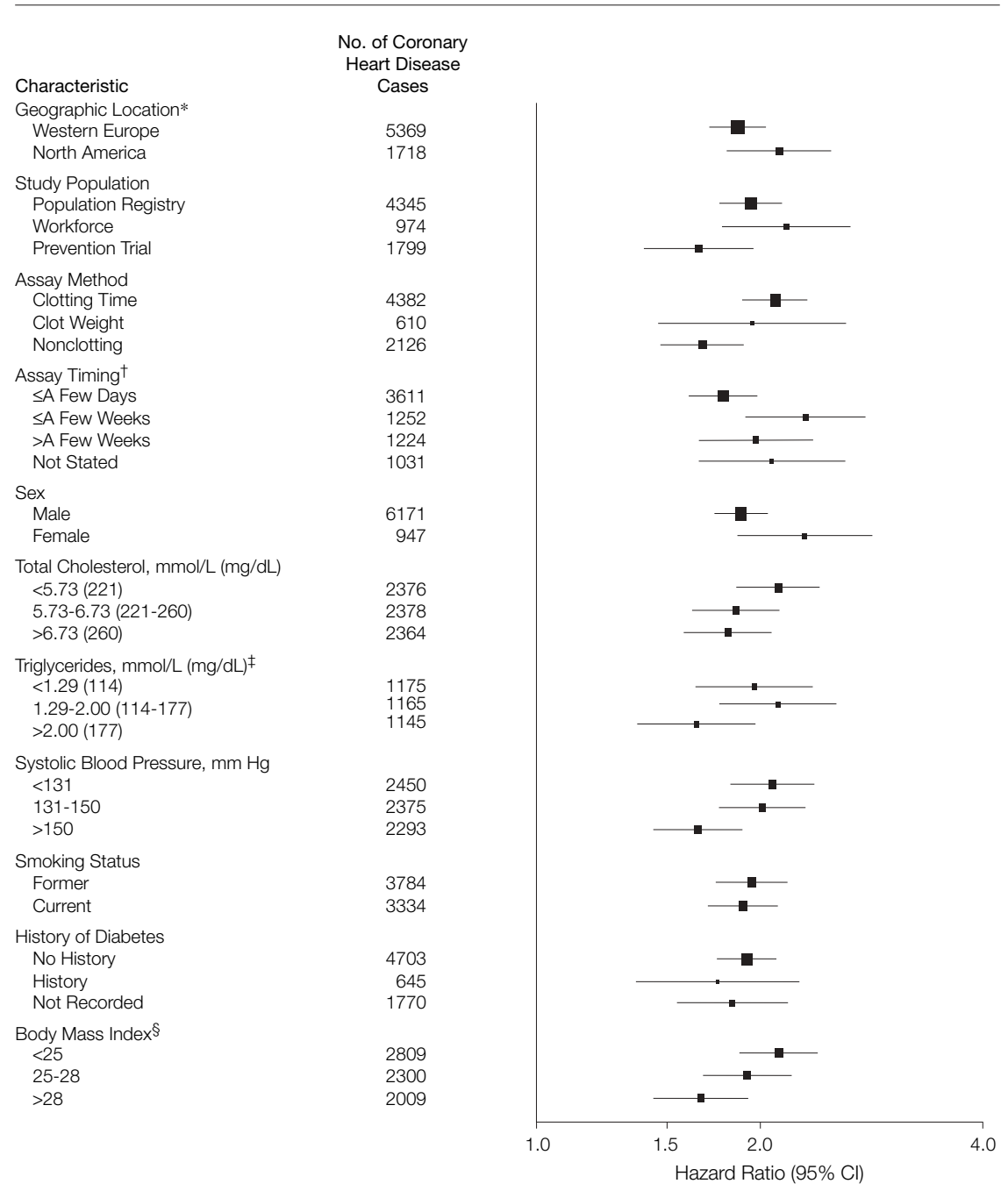

Adjusted for age at screening, smoking status, systolic blood pressure, total cholesterol, and body mass index and stratified by sex, cohort, and trial group. $\mathrm{Cl}$ indicates confidence interval. The size of the data markers is proportional to the inverse of the variances of the hazard ratios.

* Osaka cohort has been excluded from geographical location.

tRelates to time following blood collection.

\#Tertiles of total cholesterol, triglycerides, systolic blood pressure, and body mass index were defined by their respective distributions among coronary heart disease cases.

$\S$ Calculated as weight in kilograms divided by height in meters squared. 


\section{$2.23(95 \% \mathrm{CI}, 1.59-3.14)$ to 1.78}

(95\% CI, 1.19-2.66) after adjustment for age, sex, several established coronary risk factors, and C-reactive protein. The numbers of other vascular and nonvascular disease outcomes were too few in this subset to enable reliable analyses adjusted for C-reactive protein. Additional figures are available at http:// www.phpc.cam.ac.uk/FSC/FSC _index.htm.

\section{COMMENT}

The present meta-analysis involves individual participant data from 31 prospective studies of major cardiovascular diseases and nonvascular mortality among 154211 individuals without known cardiovascular disease at baseline. It provides the first reliable demonstration that fibrinogen is associated with the age-specific incidence rates of CHD, stroke (especially nonhemor-

Figure 5. Adjusted Hazard Ratios for Stroke per 1-g/L Increase in Usual Fibrinogen Level

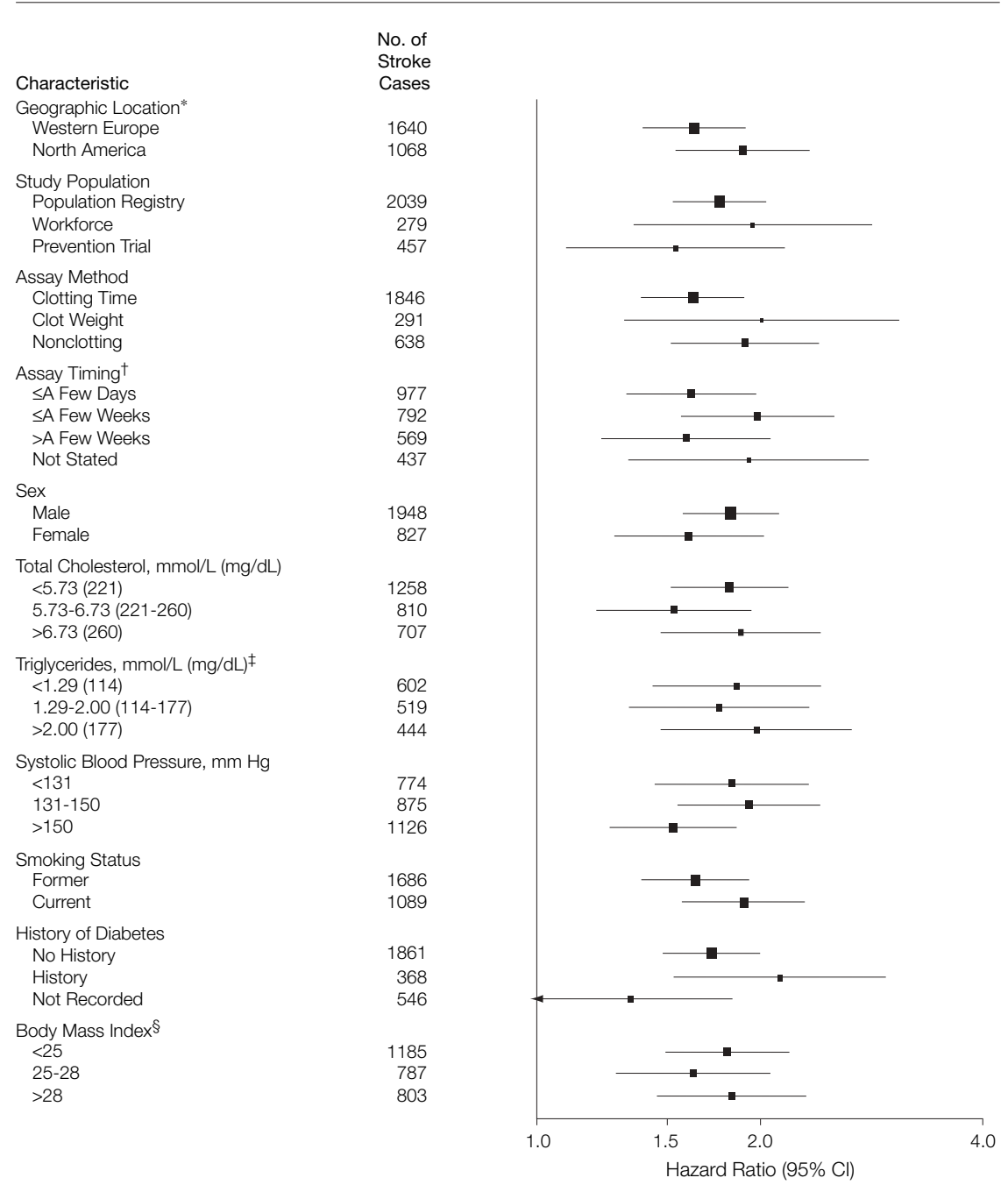

Adjusted for age at screening, smoking status, systolic blood pressure, total cholesterol, and body mass index and stratified by sex, cohort, and trial group. $\mathrm{Cl}$ indicates confidence interval. The size of the data markers is proprotional to the inverse of the variances of the hazard ratios.

* Osaka cohort has been excluded from geographical location.

tRelates to time following blood collection.

¥Tertiles of total cholesterol, triglycerides, systolic blood pressure, and body mass index were defined by their respective distributions among coronary heart disease cases.

$\S$ Calculated as weight in kilograms divided by height in meters squared. rhagic stroke), other (eg, non-CHD, nonstroke) vascular mortality, and, interestingly, of the aggregate of all nonvascular causes (mainly comprising cancer). These data demonstrate that throughout the range of fibrinogen levels recorded in Western populations, the proportional differences in risk of each of these end points associated with a given absolute difference in usual fibrinogen are generally similar at all fibrinogen levels (ie, the relationships are approximately log linear). The present meta-analysis indicates that the associations of fibrinogen level with CHD or with stroke do not differ substantially by baseline levels of established risk factors such as sex, smoking, blood pressure, serum lipid levels, or several features of study design.

The associations between fibrinogen level and the incidence of a broad range of different chronic diseases are particularly striking, including not just major ischemic cardiovascular diseases but also the aggregate of nonvascular mortality. ${ }^{6,13}$ The magnitude of the associations persisted largely unchanged in analyses restricted to never smokers and to disease cases recorded several years after the baseline examination, reducing the likelihood that they were mainly due to cigarette smoking habits and/or early cardiovascular disease. It has been suggested that such associations reflect a response to cumulative environmental stressors (as indicated by circulating levels of fibrinogen and other inflammatory factors), which may modify the risk, progression, and outcomes of various chronic diseases. ${ }^{56}$ Although the lack of specificity in the associations of fibrinogen level with different vascular and nonvascular outcomes does not necessarily exclude a causative role for fibrinogen in ischemic cardiovascular diseases, there remains scope in these estimates for biases due to residual (or unmeasured) confounding by other factors.

Fibrinogen levels were correlated with several established risk factors (such as blood pressure and serum cholesterol levels). After adjustment for baseline values of such risk factors, the 
HRs for CHD and stroke each reduced to about 1.8 per $1-\mathrm{g} / \mathrm{L}$ increase in usual fibrinogen level. These confounding factors probably have been measured with some error so substantial residual confounding may remain. ${ }^{55}$ For example, the within-person correlations on measurements of blood cholesterol levels and blood pressure values taken a few years apart are only about two thirds for each. ${ }^{47}$ Hence, adjustment of the relationship between fibrinogen level and CHD or stroke for the measured values of smoking, blood pressure, and serum cholesterol level (and other confounders) may have only reduced the associations by approximately two thirds of the amount that the adjustment for usual fibrinogen levels would have done. Moreover, more complete adjustment may have been achieved by correction for variables that more directly reflect the relevant confounding factors and/or preexisting disease (such as apolipoproteins B and A1 rather than direct measurement of cholesterol subfractions,${ }^{57}$ or indices of subclinical atherosclerosis [eg, the anklebrachial pressure index ${ }^{58}$ or carotid intimamedia thickness $\left.{ }^{59}\right]$ ), but such considerations are difficult to quantify. After adjustment for established risk factors, the association between fibrinogen level and risk of CHD was essentially unchanged following additional adjustment for C-reactive protein in the 7011 participants with available $\mathrm{C}$-reactive protein measurements. Further investigation of this association in larger numbers of participants with both fibrinogen levels and C-reactive protein values will be required to assess this more reliably.

Assessment of the likelihood of any causal relationships of fibrinogen level with disease will require research strategies that can minimize potential residual biases, such as investigation of the genetic determinants of fibrinogen level in large-scale observational studies (ie, "Mendelian randomization" 60,61 and B. Keavney, MD, J. Danesh, DPhil, S. Parish, DPhil, et al, unpublished data, 2005) or randomized trials of selective fibrinogen-lowering agents. This meta-
Table 3. Age-, Sex-, and Cohort-Adjusted Hazard Ratios per 1-g/L Increase in Usual Plasma Fibrinogen Level

\begin{tabular}{|c|c|c|c|c|}
\hline \multirow{2}{*}{$\begin{array}{c}\text { Factors in the } \\
\text { Progressive Adjustment }\end{array}$} & \multicolumn{2}{|c|}{$\begin{array}{l}\text { Data From } 31 \text { Cohorts* } \\
\quad(n=154211)\end{array}$} & \multicolumn{2}{|c|}{$\begin{array}{l}\text { Data From 14 Cohorts } † \\
\quad(n=72105)\end{array}$} \\
\hline & $\mathrm{HR}(95 \% \mathrm{Cl})$ & $\chi^{2}$ & $\mathrm{HR}(95 \% \mathrm{Cl})$ & $\chi^{2}$ \\
\hline \multicolumn{5}{|l|}{ Coronary heart disease } \\
\hline Age at screening, sex, and cohort & $2.42(2.24-2.60)$ & 551 & $2.60(2.31-2.93)$ & 246 \\
\hline Plus smoking status & $2.13(1.98-2.30)$ & 391 & $2.31(2.04-2.61)$ & 181 \\
\hline Plus total cholesterol & $2.06(1.91-2.22)$ & 347 & $2.22(1.96-2.51)$ & 162 \\
\hline Plus systolic blood pressure & $1.98(1.84-2.14)$ & 313 & $2.13(1.88-2.41)$ & 145 \\
\hline Plus body mass index & $1.93(1.79-2.08)$ & 285 & $2.08(1.84-2.35)$ & 133 \\
\hline Plus HDL cholesterol $\neq$ & & & $1.97(1.74-2.23)$ & 114 \\
\hline Plus LDL cholesterol§ & & & $1.85(1.64-2.10)$ & 93 \\
\hline Plus alcohol consumption§ & & & $1.82(1.61-2.07)$ & 87 \\
\hline Plus triglycerides§ & & & $1.83(1.62-2.08)$ & 89 \\
\hline Plus history of diabetes§ & & & $1.82(1.60-2.06)$ & 87 \\
\hline \multicolumn{5}{|l|}{ Stroke } \\
\hline Age at screening, sex, and cohort & $2.06(1.83-2.33)$ & 138 & $2.28(1.93-2.68)$ & 97 \\
\hline Plus smoking status & $1.89(1.67-2.13)$ & 103 & $2.08(1.76-2.45)$ & 75 \\
\hline Plus total cholesterol & $1.87(1.66-2.12)$ & 101 & $2.06(1.74-2.43)$ & 72 \\
\hline Plus systolic blood pressure & $1.76(1.56-2.00)$ & 82 & $1.92(1.62-2.27)$ & 59 \\
\hline Plus body mass index & $1.75(1.55-1.98)$ & 78 & $1.92(1.62-2.27)$ & 57 \\
\hline Plus HDL cholesterol & & & $1.87(1.58-2.21)$ & 52 \\
\hline Plus LDL cholesterol§ & & & $1.85(1.56-2.19)$ & 50 \\
\hline Plus alcohol consumption§ & & & $1.83(1.54-2.17)$ & 48 \\
\hline Plus triglycerides§ & & & $1.84(1.55-2.19)$ & 49 \\
\hline Plus history of diabetes§ & & & $1.82(1.54-2.16)$ & 48 \\
\hline \multicolumn{5}{|l|}{ Other vascular mortality } \\
\hline Age at screening, sex, anc & $2.76(2.28-3.35)$ & 106 & $3.51(2.63-4.70)$ & 72 \\
\hline Plus smoking status & $2.49(2.05-3.04)$ & 83 & $3.23(2.41-4.34)$ & 62 \\
\hline Plus total cholesterol & 2.49 (2.04-3.03) & 83 & $3.24(2.42-4.35)$ & 62 \\
\hline Plus systolic blood pressure & $2.41(1.98-2.93)$ & 76 & $3.10(2.31-4.17)$ & 57 \\
\hline Plus body mass index & $2.33(1.91-2.84)$ & 69 & $3.10(2.30-4.17)$ & 55 \\
\hline Plus HDL cholesterol & & & $3.14(2.33-4.24)$ & 56 \\
\hline Plus LDL cholesterol§ & & & $3.19(2.36-4.30)$ & 58 \\
\hline Plus alcohol consumption§ & & & $3.15(2.33-4.25)$ & 56 \\
\hline Plus triglycerides§ & & & $3.19(2.36-4.30)$ & 57 \\
\hline Plus history of diabetes§ & & & $3.11(2.31-4.20)$ & 55 \\
\hline \multicolumn{5}{|l|}{ Nonvascular mortality } \\
\hline Age at screening, sex, and cohort & $2.03(1.90-2.18)$ & 392 & $2.05(1.84-2.28)$ & 173 \\
\hline Plus smoking status & $1.79(1.67-1.93)$ & 257 & $1.87(1.68-2.09)$ & 130 \\
\hline Plus total cholesterol & $1.81(1.69-1.95)$ & 268 & $1.90(1.71-2.12)$ & 137 \\
\hline Plus systolic blood pressure & $1.80(1.68-1.94)$ & 264 & $1.88(1.69-2.09)$ & 131 \\
\hline Plus body mass index & $1.84(1.71-1.98)$ & 280 & $1.98(1.78-2.21)$ & 152 \\
\hline Plus HDL cholesterol & & & $2.00(1.79-2.23)$ & 152 \\
\hline Plus LDL cholesterol§ & & & $2.06(1.85-2.30)$ & 168 \\
\hline Plus alcohol consumption§ & & & $2.06(1.85-2.30)$ & 167 \\
\hline Plus triglycerides§ & & & $2.07(1.85-2.31)$ & 168 \\
\hline Plus history of diabetes§ & & & $2.05(1.84-2.29)$ & 165 \\
\hline
\end{tabular}

Abbreviations: Cl, confidence interval; HDL, high-density lipoprotein; HR, hazard ratio; LDL, low-density lipoprotein. *Complete information on age, sex, smoking status, total cholesterol, systolic blood pressure, and body mass index. There were 7118 coronary heart disease cases, 2775 stroke cases, 992 cases of other vascular mortality, and 8007 nonvascular deaths.

tComplete information on age, sex, smoking status, cholesterol (total, high-density lipoprotein, and low-density lipoprotein), systolic blood pressure, body mass index, alcohol consumption, triglycerides, and history of diabetes. There were 2534 coronary heart disease cases, 1370 stroke cases, 385 cases of other vascular mortality, and 3157 nonvascular deaths.

¥HDL cholesterol has been substituted for total cholesterol in these adjusted models.

§HDL and LDL cholesterol have been substituted for total cholesterol in these adjusted models. 
analysis provides the most comprehensive and detailed description, to date, of the observational epidemiological associations between plasma fibrinogen level and a range of different chronic disease outcomes and demonstrates moderately strong associations in a wide range of circumstances.

Authors/Writing Committee of the Fibrinogen Studies Collaboration: John Danesh, DPhil, Department of Public Health and Primary Care, University of Cambridge, Cambridge, England; Sarah Lewington, DPhil, Clinical Trial Service Unit, University of Oxford, Oxford, England; Simon G. Thompson, DSc, Medical Research Council Biostatistics Unit, Institute of Public Health, Cambridge, England; Gordon D. O. Lowe, FRCP, Division of Cardiovascular and Medical Sciences, University of Glasgow, Glasgow, Scotland; Rory Collins, FMedSci, Clinical Trial Service Unit, University of Oxford, Oxford, England.

Authors/Members of the Fibrinogen Studies Collaboration: AMIS: J. B. Kostis, A. C. Wilson. Atherosclerosis Risk in Communities Study: A. R. Folsom, K. Wu. BIP Registry: M. Benderly, U. Goldbourt. Bruneck Study: J. Willeit, S. Kiechl. Caerphilly Study: J. W. G. Yarnell, P. M. Sweetnam, P. C. Elwood (this prospective cohort study was undertaken by the former UK Medical Research Council Epidemiology Unit [South Wales] and was funded by the Medical Research Council/Institute of Public Health; its data archive is maintained by the Department of Social Medicine, University of Bristol). Cardiovascular Health Study: M. Cushman, B. M. Psaty, R. P. Tracy (see http:// chs-nhlbi.org for acknowledgments). Copenhagen City Heart Study: A. Tybjærg-Hansen. ECAT Angina Pectoris Study: F. Haverkate, M. P. M. de Maat, S. G. Thompson. Edinburgh Artery Study \& Edinburgh Claudication Study: F. G. R. Fowkes, A. J. Lee, F. B. Smith. FINRISK 1992 Hemostasis Study: V. Salomaa, K. Harald, V. Rasi, E. Vahtera, P. Jousilahti, J. Pekkanen. Framingham Study: R. D'Agostino, W. B. Kannel, P. W. F. Wilson, G. Tofler. FRECVE: C. L. ArochaPiñango, A. Rodriguez-Larralde, E. Nagy, M. Mijares, R. Espinosa, E. Rodriquez-Roa, E. Ryder, M. P. Diez-Ewald, G. Campos, V. Fernandez, E. Torres, E. Coll. GISSI Prevenzione: R. Marchioli, F. Valagussa. Göteborg 1913 \& Göteborg 1933: A. Rosengren, L. Wilhelmsen, G. Lappas, H. Eriksson. GRIPS Study: P. Cremer, D. Nagel. Honolulu Heart Program: J. D. Curb, B. Rodriguez, K. Yano. Kuopio IHD Study: J. T. Salonen, K. Nyyssönen, T.-P. Tuomainen. Malmö: B. Hedblad, P. Lind. MONICA/KORA-Augsburg: $\mathrm{H}$. Loewel, W. Koenig. Northwick Park Heart Study I: T. W. Meade, J. A. Cooper, B. De Stavola, C. Knottenbelt. Northwick Park Heart Study II: G. J. Miller, J. A. Cooper, K. A. Bauer, R. D. Rosenberg. Osaka Study: S. Sato, A. Kitamura, Y. Naito, H Iso. Platelet Activation and Inflammation Study: V. Salomaa, K. Harald, V. Rasi, E. Vahtera, P. Jousilahti, T. Palosuo. PRIME Study: P. Ducimetiere, P. Amouyel, D. Arveiler, A. E. Evans, J. Ferrieres, I. Juhan-Vague, A. Bingham. PROCAM Study: H. Schulte, G. Assmann. Quebec Cardiovascular Study: B. Cantin, B. Lamarche, J.-P. Després, G. R. Dagenais. Scottish Heart Health Study: H. Tunstall-Pedoe, G. D. O. Lowe, M. Woodward. Speedwell: Y. Ben-Shlomo, G. Davey Smith. Strong Heart Study: V. Palmieri, J. L. Yeh. Thrombosis Prevention Trial: T. W. Meade, A. Rudnicka, C. Knottenbelt, J. A. Cooper. US Physicians Health Study: P. Ridker. VITA: F. Rodeghiero, A. Tosetto. West of Scotland Coronary Prevention Study: J. Shepherd, G. D. O. Lowe, I. Ford, M. Robertson. Whitehall II: E. Brunner, M. Shipley. Zutphen Elderly Study: E. J. M. Feskens, D. Kromhout.
Authors/Independent Statistical Analyses/ Secretariat: Data management and statistical analyses were supervised and conducted by the following team of academic epidemiologists, statisticians, programmers, and data managers: R. Collins, J. Danesh (coordinator and corresponding author), A. Dickinson, B. Ireland, K. Juzwishin, S. Kaptoge, S. Lewington, G. D. O. Lowe, A. Memon, N. Sarwar, S. G. Thompson, M. Walker, J. Wheeler, I. White, A. Wood. Other Members of the Fibrinogen Studies Collaboration: P. Brennan, L. Chambless, H. W. Hense, D. Levy. Author Contributions: Dr Danesh had full access to all of the data in the study and takes responsibility for the integrity of the data and the accuracy of the data analysis.

Study concept and design: Danesh, Lewington, Lowe, Collins.

Acquisition of data: Authors/Members of the Fibrinogen Studies Collaboration, with data harmonization performed by Dickinson, Walker, Wheeler, Lewington, Sarwar, Danesh.

Analysis and interpretation of data: Danesh, Lewington, Thompson, Wheeler, Ireland, Sarwar, Kaptoge, Juzwishin, Dickinson, Walker, Memon, Wood, White, Lowe, Collins, Authors/Members of the Fibrinogen Studies Collaboration.

Drafting of the manuscript: Danesh.

Critical revision of the manuscript for important intellectual content: Authors/Members of the Fibrinogen Studies Collaboration, Danesh, Lewington, Thompson, Lowe, Collins.

Statistical analysis: Lewington, Thompson, Wheeler, Ireland, Sarwar, Kaptoge, Juzwishin, Dickinson, Walker, Memon, Wood, White, Collins, Danesh.

Obtained funding: Danesh, Lowe, Collins.

Administrative, technical, or material support: Secretariat (see below)

Study supervision: Danesh, Lewington, Thompson, Lowe, Collins.

Financial Disclosures: None reported.

Funding/Support: The Fibrinogen Studies Collaboration is supported by special project grant 002/02 from the British Heart Foundation.

Role of the Sponsor: The British Heart Foundation had no role in the design, conduct, data management and analysis; or in the manuscript preparation or review; or in the authorization for submission.

Acknowledgment: The following individuals commented helpfully on the article but were not compensated: François Bonnici, MBBS, Nita Gandhi Forouhi, MRCP, Teri Manolio, MD, PhD, and Nicholas Wald, FRS. Vanessa White provided secretarial support.

\section{REFERENCES}

1. Tybjaerg-Hansen A, Agerholm-Larsen B, Humphries $S E$, et al A common mutation $(\mathrm{G}-455 \rightarrow A)$ in the betafibrinogen promoter is an independent predictor of plasma fibrinogen, but not of ischemic heart disease: a study of 9,127 individuals based on the Copenhagen City Heart Study. J Clin Invest. 1997;99: 3034-3039.

2. Kannel WB, Wolf PA, Castelli WP, D'Agostino RB. Fibrinogen and risk of cardiovascular disease: the Framingham Study. JAMA. 1987;258:1183 1186

3. Mijares ML, Rodriguez-Larralde A, Espinosa R, et al. Fibrinogeno y otres parametros hemostaticos en la enfermedad coronaria isquemica. Inform Med. 2000;2: 613-628.

4. Rosengren A, Wilhelmsen L. Fibrinogen, coronary heart disease and mortality from all causes in smokers and nonsmokers: the study of men born in 1933. I Intern Med. 1996:239:499-507.

5. Cremer P, Nagel D, Mann H, et al. Ten-year follow-up results from the Goettingen Risk, Incidence and Prevalence Study (GRIPS), I: risk factors for myocardial infarction in a cohort of 5790 men. Atherosclerosis. 1997:129:221-230.
6. Yano K, Grove JS, Chen R, et al. Plasma fibrinogen as a predictor of total and cause-specific mortality in elderly Japanese-American men. Arterioscler Thromb Vasc Biol. 2001;21:1065-1070.

7. Lind $P$, Hedblad B, Stavenow L, et al. Influence of plasma fibrinogen levels on the incidence of myocardial infarction and death is modified by other inflammation-sensitive proteins: a long-term cohort study. Arterioscler Thromb Vasc Biol. 2001:21:452-458.

8. Krobot K, Hense HW, Cremer P, et al. Determinants of plasma fibrinogen: relation to body weight waist-to-hip ratio, smoking, alcohol, age, and sex: results from the second MONICA Augsburg survey 1989-1990. Arterioscler Thromb. 1992;12:780-788. 9. Sato S, Nakamura M, lida M, et al. Plasma fibrinogen and coronary heart disease in urban Japanese. Am J Epidemiol. 2000;152:420-423.

10. Jousilahti $P$, Salomaa $V$, Rasi $V$, et al. The association of $C$-reactive protein, serum amyloid $A$ and fibrinogen with prevalent coronary heart diseasebaseline findings of the PAIS project. Atherosclerosis. 2001;156:451-456

11. Scarabin PY, Aillaud MF, Amouyel P, et al. Associations of fibrinogen, factor VII and PAI-1 with baseline findings among 10,500 male participants in a prospective study of myocardial infarction-the PRIME Study (Prospective Epidemiological Study of Myocardial Infarction). Thromb Haemost. 1998:80:749-756 12. Cantin B, Despres JP, Lamarche B, et al. Association of fibrinogen and lipoprotein(a) as a coronary heart disease risk factor in men (Quebec Cardiovascular Study). Am J Cardiol. 2002;89:662-666.

13. Woodward M, Lowe GDO, Rumley A, TunstallPedoe $\mathrm{H}$. Fibrinogen as a risk factor for coronary heart disease and mortality in middle-aged men and wom en (Scottish Heart Health Study). Eur Heart J. 1998;19: 55-62.

14. Rodeghiero F, Tosetto A. The epidemiology of inherited thrombophilia: the VITA Project. Thromb Haemost. 1997;78:636-640.

15. Lowe G, Rumley A, Norrie J, et al. Blood rheology, cardiovascular risk factors, and cardiovascular disease: the West of Scotland Coronary Prevention Study. Thromb Haemost. 2000;84:553-558.

16. Feskens E, Kromhout D. Fibrinogen and factor VII activity as risk factors for cardiovascular disease in an elderly cohort. Can J Cardiol. 1997;13:282B

17. Kostis JB, Baughman DJ, Kuo PT. Association of recurrent myocardial infarction with hemostatic factors: a prospective study. Chest. 1982;81:571-575. 18. Benderly M, Graff E, Reicher-Reiss H, et al; Bezafibrate Infarction Prevention (BIP) Study Group. Fi brinogen is a predictor of mortality in coronary heart disease patients. Arterioscler Thromb Vasc Biol. 1996 16:351-356.

19. Thompson SG, Kienast J, Pyke SD, et al: European Concerted Action on Thrombosis and Disabilities Angina Pectoris Study Group. Hemostatic factors and the risk of myocardial infarction or sudden death in patients with angina pectoris. N Eng/ J Med. 1995; 332:635-641.

20. Smith FB, Rumley $A$, Lee AJ, et al. Haemostatic factors and prediction of ischaemic heart disease and stroke in claudicants. Br J Haematol. 1998;100:758 763.

21. GISSI-Prevenzione Investigators. Dietary supplementation with $\mathrm{N}-3$ polyunsaturated fatty acids and vitamin $\mathrm{E}$ after myocardial infarction: results of the GISSI-Prevenzione trial. Lancet. 1999;354 447-455

22. Ma J, Hennekens $\mathrm{CH}$, Ridker PM, Stampfer $\mathrm{MJ}$. A prospective study of fibrinogen and risk of myo cardial infarction in the Physicians' Health Study. J Am Coll Cardiol. 1999:33:1347-1352.

23. Brunner $E$, Davey-Smith G, Marmot $M$, et al. Childhood social circumstances and psychosocial and behavioural factors as determinants of plasma fibrinogen. Lancet. 1996;347:1008-1013. 
24. Folsom AR, Wu KK, Rosamond WD, et al. Prospective study of hemostatic factors and incidence of coronary heart disease: the Atherosclerosis Risk in Communities (ARIC) Study. Circulation. 1997;96: 1102-1108.

25. Willeit J, Kiechl S, Oberhollenzer F, et al. Distinct risk profiles of early and advanced atherosclerosis: prospective results from the Bruneck Study. Arterioscler Thromb Vasc Biol. 2000;20:529-537.

26. Sweetnam PM, Yarnell JW, Lowe GDO, et al. The relative power of heat-precipitation nephelometric and clottable (Clauss) fibrinogen in the prediction of ischaemic heart disease: the Caerphilly and Speedwell studies. Br J Haematol. 1998;100:582-588.

27. Tracy RP, Arnold AM, Ettinger W, et al. The relationship of fibrinogen and factors VII and VIII to incident cardiovascular disease and death in the elderly: results from the cardiovascular health study. Arterioscler Thromb Vasc Biol. 1999:19:1776-1783. 28. Smith FB, Lee AJ, Fowkes FG, et al. Hemostatic factors as predictors of ischemic heart disease and stroke in the Edinburgh Artery Study. Arterioscler Thromb Vasc Biol. 1997:17:3321-3325.

29. Salomaa V, Rasi V, Kulathinal $S$, et al. Hemostatic factors as predictors of coronary events and total mortality: the FINRISK '92 Hemostasis Study. Arterioscler Thromb Vasc Biol. 2002:22:353-358.

30. Wilhelmsen L, Svardsudd K, Korsan-Bengtsen K, et al. Fibrinogen as a risk factor for stroke and myocardial infarction. N Engl J Med. 1984;311:501505

31. Lakka TA, Salonen JT. Moderate to high intensity conditioning leisure time physical activity and high cardiorespiratory fitness are associated with reduced plasma fibrinogen in Eastern Finnish men. J Clin Epidemiol. 1993;46:1119-1127.

32. Meade TW, Ruddock V, Stirling Y, et al. Fibrinolytic activity, clotting factors, and long-term incidence of ischaemic heart disease in the Northwick Park Heart Study. Lancet. 1993;342:1076-1079.

33. Cooper JA, Miller GJ, Bauer KA, et al. Comparison of novel hemostatic factors and conventional risk factors for prediction of coronary heart disease. Circulation. 2000:102:2816-2822.

34. Heinrich J, Balleisen L, Schulte $\mathrm{H}$, et al. Fibrinogen and factor VII in the prediction of coronary risk: results from the PROCAM study in healthy men [published erratum appears in Arterioscler Thromb. 1994;14:1392]. Arterioscler Thromb. 1994;14: 54-59.

35. Caerphilly and Speedwell Collaborative Group.
Caerphilly and Speedwell collaborative heart disease studies. J Epidemiol Community Health. 1984;38:259. 262.

36. Palmieri V, Celentano A, Roman MJ, et al. Relation of fibrinogen to cardiovascular events is independent of preclinical cardiovascular disease: the Strong Heart Study. Am Heart J. 2003;145:467-474

37. Medical Research Council's General Practice Research Framework. Thrombosis prevention trial: randomised trial of low-intensity oral anticoagulation with warfarin and low-dose aspirin in the primary prevention of ischaemic heart disease in men at increased risk. Lancet. 1998:351:233-241.

38. Danesh J, Collins R, Peto R, Lowe GDO. Haematocrit, viscosity, erythrocyte sedimentation rate: metaanalyses of prospective studies of coronary heart disease. Eur Heart J. 2000;21:515-520.

39. Lowe GDO. Fibrinogen and cardiovascular disease: historical introduction. Eur Heart J. 1995;16(suppl A):2-5

40. Smith EB. Fibrinogen, fibrin and the arterial wall. Eur Heart J. 1995;16(suppl A):11-14.

41. Smith EB, Crosbe I. Fibrinogen and fibrin in atherogenesis. In: Ernst E, Koenig W, Lowe GDO, Meade TW, eds. Fibrinogen: A "New" Cardiovascular Risk Factor. Vienna, Austria: Blackwell-MZV; 1992: 4-10.

42. Folsom AR. Epidemiology of fibrinogen. Eur Heart J. 1995;16(suppl A):21-23.

43. Danesh J, Collins R, Appleby P, Peto R. Association of fibrinogen, C-reactive protein, albumin, or leukocyte count with coronary heart disease: metaanalyses of prospective studies. JAMA. 1998;279:14771482.

44. Ernst E, Resch KL. Fibrinogen as a cardiovascular risk factor: a meta-analysis and review of the literature. Ann Intern Med. 1993:118:956-963.

45. Maresca G, Di Blasio A, Marchioli R, Di Minno G. Measuring plasma fibrinogen to predict stroke and myocardial infarction: an update. Arterioscler Thromb Vasc Biol 1999:19:1368-1377.

46. Rothwell PM, Howard SC, Power DA, et al. Fibrinogen concentration and risk of ischemic stroke and acute coronary events in 5113 patients with transient ischemic attack and minor ischemic stroke. Stroke. 2004;35:2300-2305.

47. Clarke R, Shipley M, Lewington S, et al. Underestimation of risk associations due to regression dilution in long-term follow-up of prospective studies. Am J Epidemiol. 1999;150:341-353.

48. Fibrinogen Studies Collaboration. Collaborative meta-analysis of prospective studies of plasma fibrinogen and cardiovascular disease. Eur J Cardiovasc Prev Rehabil. 2004;11:9-17.

49. Prospective Studies Collaboration. Age-specific relevance of usual blood pressure to vascular mortality: a meta-analysis of individual data for one million adults in 61 prospective studies. Lancet. 2002;360:1903-1913. 50. Easton DF, Peto J, Babiker AG. Floating absolute risk: an alternative to relative risk in survival and casecontrol analysis avoiding an arbitrary reference group. Stat Med. 1991;10:1025-1035.

51. Lowe GDO, Rumley A, Mackie IJ. Plasma fibrinogen. Ann Clin Biochem. 2004;41:430-440.

52. Blood rheology and hyperviscosity syndromes. Baillieres Clin Haematol. 1987;1:597-867.

53. Rosner B, Willett WC, Spiegelman D. Correction of logistic regression relative risk estimates and confidence intervals for systematic within-person measurement error. Stat Med. 1989;8:1051-1069.

54. Higgins JP, Thompson SG. Quantifying heterogeneity in a meta-analysis. Stat Med. 2002;21:1539 1558.

55. Greenland S. The effect of misclassification in the presence of covariates. Am J Epidemiol. 1980;112:564 569.

56. Lowe GDO. Fibrinogen measurement to assess the risk of arterial thrombosis in individual patients: not yet. J Thromb Haemost. 2005;3:635-637. 57. Walldius G, Jungner I, Holme I, et al. High apolipoprotein B, low apolipoprotein A-I, and improvement in the prediction of fatal myocardial infarction (AMORIS study): a prospective study. Lancet. 2001 358:2026-2033.

58. Lowe GDO, Fowkes FG, Dawes J, et al. Blood viscosity, fibrinogen, and activation of coagulation and leukocytes in peripheral arterial disease and the normal population in the Edinburgh Artery Study. Circulation. 1993;87:1915-1920.

59. Lee AJ, Mowbray PI, Lowe GDO, et al. Blood viscosity and elevated carotid intima-media thickness in men and women: the Edinburgh Artery Study. Circulation. 1998;97:1467-1473.

60. Youngman LD, Keavney BD, Palmer A. Plasma fibrinogen and fibrinogen genotypes in 4685 cases of myocardial infarction and in 6002 controls: test of causality by 'Mendelian randomisation.' Circulation. 2000; 102(suppl II):31-32.

61. Davey-Smith G, Ebrahim S. "Mendelian randomization": can genetic epidemiology contribute to understanding environmental determinants of disease? Int J Epidemiol. 2003;32:1-22. 
J. A. C. Delaney, MA, MSc

chris.delaney@clinepi.mcgill.ca

Division of Clinical Epidemiology

Royal Victoria Hospital

Montreal, Quebec

Financial Disclosures: None reported.

1. Brown GK, Ten Have T, Henriques GR, Xie SX, Hollander JE, Beck AT. Cognitive therapy for the prevention of suicide attempts: a randomized controlled trial. JAMA. 2005;294:563-570.

2. Altman DG, Schulz KF, Moher D, et al. The revised CONSORT statement for reporting randomized trials: explanation and elaboration. Ann Intern Med. 2001 134:663-694

3. Wampold BE, Minami T, Tierney SC, Baskin TW, Bhati KS. The placebo is powerful: estimating placebo effects in medicine and psychotherapy from randomized clinical trials. J Clin Psychol. 2005;61:835-854.

In Reply: Drs Tepper and Whitehead and Messrs Filion and Delaney express concern about several variables that may account for our study results. They suggest that confounding related to either baseline marital and employment status or lack of any treatment during follow-up could be the underlying explanation for the observed difference in repeat suicide attempt rates between the 2 groups.

We created Cox regression models adjusting for these factors. They did not explain the intervention effect when controlling for marital and employment status (hazard ratio [HR], 0.51 [95\% confidence interval $\{C I\}, 0.25-1.01]$; Wald $\left.\chi_{1}^{2}=3.72 ; P=.054\right)$. After controlling for lack of treatment during the 18-month follow-up period, we found a HR of 0.41 (95\% CI, 0.20-0.80; Wald $\chi_{1}^{2}=6.42 ; P=.01$ ). The increased significance of the cognitive therapy effect after controlling for lack of treatment is explained by an association between no treatment and a reduced suicide reattempt rate relative to those patients who received some treatment (HR, 0.38 [95\% CI, 0.19-0.74]; Wald $\left.\chi_{1}^{2}=7.91 ; P=.005\right)$. In contrast, neither marital status $(P=.23)$ or employment status $(P=.89)$ were significantly related to suicide reattempt status, with the differences in statistical significance after adjustment likely due to random variation.

Tepper and Whitehead also note that just a few misclassified or unknown suicide attempts could have substantial effect on the comparison between the 2 groups. To address this concern, sensitivity analyses were conducted to determine the potential impact of the discovery of a suicide attempt among those individuals who dropped out of the study. When a repeat suicide attempt at the time of drop out was assumed for 1 of the patients in the control group, the survival results did not change inferentially (Wald $\chi_{1}^{2}=4.4$ and $P=.04 ; \log$-rank $\chi_{1}^{2}=4.6$ and $P=.03$ ). When a repeat suicide attempt at the time of drop out was assumed for 1 of the patients in the intervention condition, the results became nonsignificant at the .05 level but still showed a trend (Wald $\chi_{1}^{2}=3.3$ and $P=.07 ; \log$-rank $\chi_{1}^{2}=3.4$ and $P=.07$ ). These results indicate that small changes in the number of suicide attempts during the follow-up period may have affected the results of the study.
Despite this limitation, there are important factors that support the validity of the conclusions. There was consistency in the effects of the intervention across several outcome measures (ie, depression and hopelessness) that have been identified as risk factors for suicide. ${ }^{1}$ In addition, the results of this study were consistent with those of a previous randomized trial that found a significant difference between the cognitive behavioral intervention and usual care groups for repeat suicide attempts at 6 months of follow-up. ${ }^{2}$

\section{Gregory K. Brown, PhD}

gregbrow@mail.med.upenn.edu

Department of Psychiatry

University of Pennsylvania

Philadelphia

Thomas Ten Have, PhD

Center for Clinical Epidemiology and Biostatistics

University of Pennsylvania

Philadelphia

Gregg R. Henriques, PhD

Department of Graduate Psychology

James Madison University

Harrisonburg, Va

Sharon X. Xie, PhD

Center for Clinical Epidemiology and Biostatistics

University of Pennsylvania

Philadelphia

Judd E. Hollander, MD

Department of Emergency Medicine

University of Pennsylvania

Philadelphia

Aaron T. Beck, MD

Department of Psychiatry

University of Pennsylvania

Philadelphia

Financial Disclosures: None reported

1. Brown GK, Beck AT, Steer RA, Grisham JR. Risk factors for suicide in psychiatric outpatients: a 20-year prospective study. J Consult Clin Psychol. 2000;68:371377.

2. Salkovskis PM, Atha C, Storer D. Cognitive behavioural problem solving in the treatment of patients who repeatedly attempt suicide: a controlled trial. $\mathrm{Br} J$ Psychiatry. 1990;157:871-876.

\section{CORRECTIONS}

Study List in Incorrect Position: In the Review entitled "Plasma Fibrinogen Level and the Risk of Major Cardiovascular Diseases and Nonvascular Mortality: An Individual Participant Meta-analysis" published in the October 12, 2005, issue of JAMA (2005;294:1799-1809), a study list appeared in the wrong order. On page 1808 , the "Independent Statistical Analyses/Secretariat" should have been the "Authors/Independent Statistical Analyses/Secretariat" and the group should have appeared before the "Other Members of the Fibrinogen Studies Collaboration."

Incorrect Name of Institution: In the Commentary entitled "Filling the Gaps in Bariatric Surgical Research" published in the October 19, 2005, issue of JAMA (2005; 294:1957-1960), the wrong institution name appeared. On page 1960, in column 1, in line 1, the "University of Pennsylvania Medical Center Health Plan" should have been the "University of Pittsburgh Medical Center Health Plan." 